\title{
Optical Measurements of an Atmospheric Pressure Microplasma Jet Aiming Surface Treatment
}

\author{
J. C. Nascimento ${ }^{1}$, E. C. B. B. Aragão ${ }^{1}$, A. D. Fernandes ${ }^{1}$, F. T. F. Barbosa ${ }^{1}$, L. M. S. Costa ${ }^{1}$, \\ D. C. Sousa ${ }^{1}$, C. Oliveira ${ }^{1,2}$, G. J. P. Abreu ${ }^{1}$, K. G. Grigorov ${ }^{1,3}$, P. Getsov ${ }^{3}$, R. S. Pessoa ${ }^{1,4}$, \\ V. W. Ribas ${ }^{1}$, B. N. Sismanoglu ${ }^{1, *}$ \\ ${ }^{1}$ Technological Institute of Aeronautics (ITA), Physics Department, São José dos Campos, Brazil \\ ${ }^{2}$ Laboratório Nacional de Ciência e Tecnologia do Bioetanol-CTBE/CNPEM, Campinas, Brazil \\ ${ }^{3}$ Space Research and Technology Institute, Acad. G. Bonchev Str. bl.1, Sofia, Bulgaria \\ ${ }^{4}$ University of Paraiba Valley (Univap), Nanotecnology and Plasmas Processes Laboratory, Brazil
}

\begin{abstract}
In this work stable non-thermal ac high voltage atmospheric pressure microplasma jet (APMJ) device was used for optical and electrical characterizations. It enables the generation of low power $(\sim 5 \mathrm{~W})$ microplasma jet at frequency of $60 \mathrm{~Hz}$. The jet has a visible radial diameter of approximately $1.5 \mathrm{~mm}$. Optical emission spectroscopy was used as a diagnostic tool to determine the gas discharge parameters as the modes temperature. The rotational temperature of $\mathrm{OH}$ radicals at the exit nozzle varies from 325 to $525 \mathrm{~K}$ for different gases where the electrical input power ranged from 3 to $10 \mathrm{~W}$. Both the electronic $(0.5-0.7 \mathrm{eV})$ and vibrational temperatures $(0.35-0.58 \mathrm{eV})$ were estimated at the same power conditions for $\mathrm{Ar}, \mathrm{He}, \mathrm{N}_{2}$, air and $\mathrm{O}_{2}+1 \%$ Ar flow rates. The highly reactive species as $\mathrm{OH}, \mathrm{O}, \mathrm{N}_{2}{ }^{+}$and the energetic photons produced between the electrodes extent along the plasma plume, both in radial and axial direction from the exit of the APMJ.
\end{abstract}

Keywords Microplasma jet, Gas temperature, Optical emission spectroscopy

\section{Introduction}

The generation of atmospheric pressure microplasma jets (APMJ) using an alternating current (ac) power supply with high frequency and high rates of gas flow recently has been subject of extended studies. This growing interest is justified by the fact that the APMJ are suitable for numerous applications that requires low gas temperature at glow regime of operation with low input power. Among them, one can emphasize the surface treatment of heath sensitive bio-medical materials, thin film deposition, reactive ion etching, bio-medical and dentistry applications, etc. For bio-medical applications, the non-thermal APMJ must be at glow discharge regime possibly at room temperature. It is desired to maintain the discharge at Townsend-glow regime to produce parallel-operated jets but the related current is very low, resulting in low power plasma which finally results in formation of a low density active species. The latter are essential for bacteriological decontamination since the formation of $\mathrm{OH}$ radicals and $\mathrm{O}$ atomsis favored. Kim et al proposed a microplasma device which operates at $20 \mathrm{kHz}$ ac power using a commercial transform for a neon light

* Corresponding author:

bogos@ita.br (B. N. Sismanoglu)

Published online at http://journal.sapub.org/ajcmp

Copyright (C) 2014 Scientific \& Academic Publishing. All Rights Reserved coupled with a set of ballast resistor and autotransformer in order to avoid excessive currents [1]. A flow of 10L.min ${ }^{-1}$ nitrogen gas was injected through the microtube and ac voltage of $13.5 \mathrm{kV}_{\mathrm{p}-\mathrm{p}}$ was applied to produce the jet, conditions suitable for use in biomedicine, as a cancer therapy. Szili et al used microplasma jet to modify surface at different treatment conditions [2]. To power the microjet at atmospheric pressure, a power delivery system consisting of a sinusoidal oscillator and an autotransformer $\left(10 \mathrm{kV}_{\mathrm{p}-\mathrm{p}}\right.$, $\left.40 \mathrm{~mA}_{\mathrm{p}-\mathrm{p}}, 40 \mathrm{kHz}\right)$ was used. When polystyrene surface is plasma treated by this method, the contact angle measurements reveal increase of the surface energy transforming it as hydrophilic. Ayan et al developed an atmospheric pressure non-thermal microjet for localized surface treatment [3]. The applied power ranged from 0.1 to $0.2 \mathrm{~W}$, useful for polyethylene substrate treatment without causing any damage. The gas mixture consists of $0.2 \mathrm{~L} \cdot \mathrm{min}^{-1}$ $\mathrm{He}+$ and $0.025 \mathrm{~L} \cdot \mathrm{min}^{-1} \mathrm{O}_{2}$ and surface functionalization (physical and chemical) was achieved. Seo et al designed a low-frequency $(20 \mathrm{kHz}$, high voltage and $\mathrm{mA}$ current) $\mathrm{He}$ and Ar APMJ and measured its optical and electrical characteristics [4]. The high intensity of $\mathrm{OH}$ radical and $\mathrm{O}$ atoms in Ar plasma was suitable for large area sterilization and indirect treatment. Microplasma jet that operates at an excitation frequency of kilohertz ac range was developed to create nonthermal glow plasma. Here, $\mathrm{He}$ and $\mathrm{O}_{2}$ APMJ were investigated by adding $\mathrm{O}_{2}$ flow, suitable for biomedical 
applications. He non-thermal microplasma jets generated at $50 \mathrm{kHz}$ ac voltage were electrical and optically characterizes [5]. It has been detected a number of highly reactive species in the plasma plume such as $\mathrm{OH}, \mathrm{O}, \mathrm{N}_{2}, \mathrm{He}$ and $\mathrm{N}_{2}{ }^{+}$at the glow discharge mode. The presence of numerous of Helines indicates higher plasma density and/or electron temperature. Great disadvantage of these microplasma jets is the high cost of both the He gas (generally L. $\mathrm{min}^{-1} \mathrm{He}$ flow are needed to obtain a stable APMJ) and the equipment (high frequency power source used).The large surface to volume ratio of these miniaturized jets makes impossible surface treatments of a large scale. Furthermore, up to date there are not enough studies to detect and reducing the emission of a number of radicals such as $\mathrm{HC}, \mathrm{CO}, \mathrm{NO}_{\mathrm{x}}, \mathrm{O}_{3}$ and $\mathrm{SO}_{\mathrm{x}}$, harmful to health if inhaled and manipulated without a due care.

Recently, an APMJ generated from micro-discharges in porous dielectric [6] or from the gap between two disk-shaped electrodes with a hole (1 $\mathrm{mm}$ of diameter) were presented [7]. Both used $\mathrm{N}_{2}$ and air to generate glow plasma powered by a high-voltage ac power supply and a commercially available transformer for neon light operated at $60 \mathrm{~Hz}$ connected to the electrodes. These gases have higher dielectric breakdown voltages compared to $\mathrm{He}$ or $\mathrm{Ar}$ and in static mode (without gas flow) it is practically impossible to produce a glow discharge at atmospheric pressure. After the breakdown transition occurs from a glow discharge to a filamentary glow or silent electric discharge $[8,9]$ in a very short time due to this electrodes configuration. To avoid thermal instability leaving to a filamentary glow or glow-to-arc transition (transition from glow to thermal discharges), they generate the non-thermal and stable glow discharge through large gas flow rate $\left(5-15 \mathrm{~L} \cdot \mathrm{min}^{-1}\right)$ that cools the plasma region removing the hot chemical species and neutrals. For surface treatment the presence of metastable states of some gases such as $\mathrm{He}(19.8 \mathrm{eV}), \mathrm{Ar}$ $(11.6 \mathrm{eV})$ and $\mathrm{N}_{2}(6.2 \mathrm{eV})$ is very interesting to produce microplasma. These energetic species react with the surface chemical structure with large efficiency. In this work, a 60 $\mathrm{Hz}$ ac APMJ device was studied to produce stable cold plasma suitable for surface treatment. The electrical and optical characteristics will be raised for a range of input power and for these gases.

\section{Experimental}

Figure 1 show the apparatus used to produce the ac microplasma jet. One transformer for neon light was used, operated at $60 \mathrm{~Hz}$. One can see in this figure the $\mathrm{Cu}$ electrodes, arranged parallel and inserted in a quartz tube. The nozzle cross-section area is about $5.3 \mathrm{~mm}^{2}$ and the gap between the circular electrodes is about $1.2 \mathrm{~mm}$. The ac power supply $(12 \mathrm{kV}, 40 \mathrm{~mA})$ is coupled with a variable autotransformer and with a ballast resistor $(50 \mathrm{k} \Omega, 100 \mathrm{~W})$ in order to avoid excessive current and to allow voltage control. This figure presents the setup used to perform optical emission spectroscopy (OES) measurements of APMJ. The plasma was confined between the electrodes, burning freely in air at atmospheric pressure (709Torr in the laboratory and 46\% local humidity) and was composed by the main gas and, in some cases, high-purity $1 \% \mathrm{H}_{2}$ was added. The addition of $\mathrm{H}_{2}$ makes possible to estimate the electron number density of the plasma from the broadening of the hydrogen atom $\mathrm{H}_{\beta}$ line. The gas connections were controlled by means of mass flow controllers MKS 247C and MKS model 1159B.The digital oscilloscope used in the experiments was a DPO7254 from Tektronix, $2.5 \mathrm{GHz}$. The highvoltageprobe (from Tektronix) was a P6015A and a current probe TCP 312 with amplifier TCPA 300. The monochromator used to capture the light from the APMJ was a IHR550 model from Horiba-JobinYvon with adiffraction grating of 1800 linesmm $^{-1}$ blazed at $500 \mathrm{~nm}$ and 2400 linesmm $^{-1}$ at $300 \mathrm{~nm}$. The entrance slit was fixed at $120 \mu \mathrm{m}$ and the respective instrumental Gaussian-type full-width at half-maximum (FWHM) $\Delta \lambda_{I}=$ $0.1 \mathrm{~nm}$ was obtained by means of an $\mathrm{Ar}-\mathrm{Hg}$ low-pressure scientific lamp and analyzing the fitting procedure for the $\mathrm{Hg}$ $435.8 \mathrm{~nm}$ strong line broadening. The spectra at the exit slit were recorded by a CCD Symphony with $1024 \times 512$ pixels and the SynerJy software was used to handle the spectra.

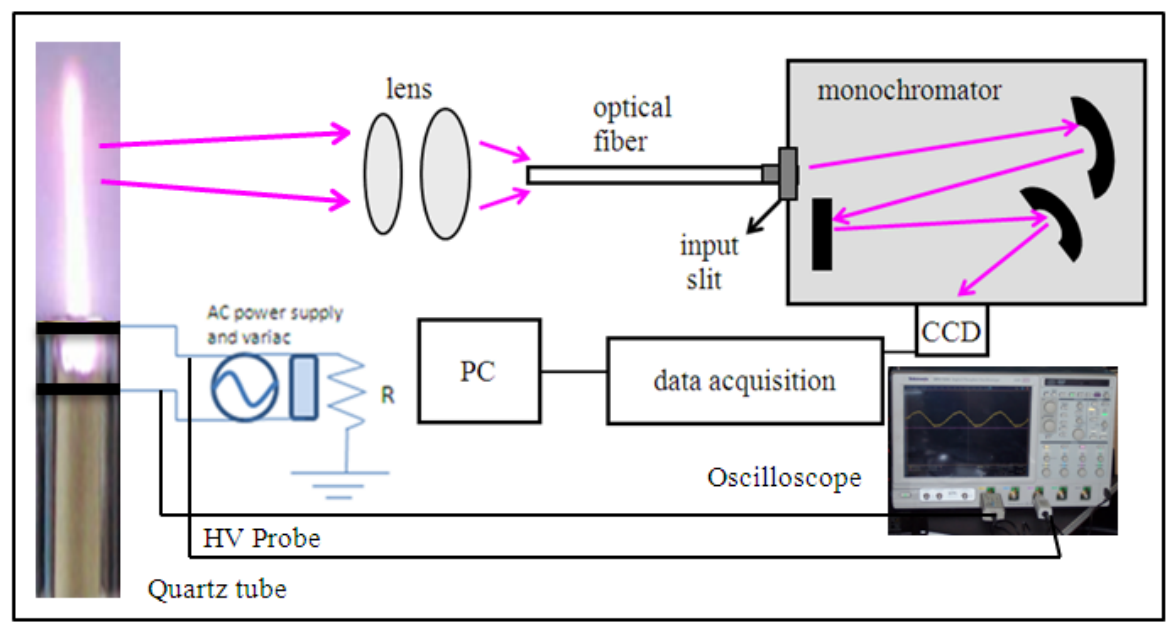

Figure 1. Schematic representation of the microplasma jet and the schematic representation of the electrical circuit (the inset left represents the photograph of air plasma jet) 


\section{Results and Discussion}

The frequency of the sinusoidal ac power supply is $60 \mathrm{~Hz}$ and the glow discharge is achieved at a gas flow varying from 3 to 10 L.min ${ }^{-1}$. In Fig. 2 a typical current-voltage waveforms of Ar APMJ is presented, at low rate of about 6 L. $\mathrm{min}^{-1}$. The discharge voltage is about $V_{p p}=1200 \mathrm{~V}\left(V_{r m s}=\right.$ $464 \mathrm{~V}$ ) for current of $I_{r m s}=12.5 \mathrm{~mA}$. A filamentary discharge is observed at gas flow below 2L. $\mathrm{min}^{-1}$. The average electric power consumption was calculated by the equation $P=\frac{1}{T} \int_{0}^{T} V(t) I(t) d t$ and results $4.8 \mathrm{~W}$.

Current and voltage measurements of stable APMJ at flow rate of $6 \mathrm{~L} \cdot \mathrm{min}^{-1}$ show sinusoidal wave forms for flows of Ar, $\mathrm{He}, \mathrm{O}_{2}+1 \% \mathrm{Ar}, \mathrm{N}_{2}$ and air gases, with rmscurrent and voltage amplitudes of: a) $464 \mathrm{~V}, 10.4 \mathrm{~mA}$; b) $410 \mathrm{~V}, 10,6 \mathrm{~mA}$; c) $515 \mathrm{~V}, 13 \mathrm{~mA}$; d) $430 \mathrm{~V}, 11.8 \mathrm{~mA}$ and e) $456 \mathrm{~V}, 12.9 \mathrm{~mA}$ respectively. The phase shift is zero and the power absorbed by the plasma is: a) $4.8 \mathrm{~W}$; b) $4.1 \mathrm{~W}$; c) $5.8 \mathrm{~W}$; d) $4.4 \mathrm{~W}$ and e) $4.9 \mathrm{~W}$ respectively. The jet elongates axially when the flow rate is increased, from 3 to $10 \mathrm{~L} \cdot \mathrm{min}^{-1}$. The highly reactive species as $\mathrm{OH}, \mathrm{O}, \mathrm{N}_{2}^{+}$and energetic photons produced between the electrodes will extent along the plasma plume, both radially and axially from the exit nozzle of the APMJ.

Figure 3 shows the main atomic and molecular emission lines from the plasma when distinct gases are used individually or mixed. For individual mixtures between $\mathrm{O}_{2}$, $\mathrm{N}_{2}$ and air with $1 \%$ Ar and for pure $\mathrm{He}$ and Ar working gas (added with $2 \% \mathrm{O}_{2}$ ), the intense lines of $\mathrm{Ar} \mathrm{I} 4 \mathrm{p}-4 \mathrm{~s}$ and $5 \mathrm{p}-$ 4s transitions $(415.8,416.4,418.2,419.1,419.8,420.1$, $425.9,427.2,427.8,433.4,434.8,437.1,437.6,437.9,440.0$, 442.6, 444.9, 447.5, 452.2, 706.7, 714.7, 727.3, 738.4, 750.3, $751.5,763.5,794.8,800.6,801.5,810.4,811.5 \mathrm{~nm})$ and $\mathrm{He}$ emission spectrum $(388.9,396.5,438.8,447.2$, 492.2, 501.6, $504.8,587.6,706.5,728.1$ and $776.8 \mathrm{~nm}$ ) have been observed. One can see intense Ar I $4 p-4$ s transition lines from 700 to $800 \mathrm{~nm}$, as well as the blue transitions $5 \mathrm{p}-4 \mathrm{~s}$ from 410 to $430 \mathrm{~nm}$ when pure Ar is used. From 420 to $450 \mathrm{~nm}$, the Ar II emission lines represent $4 p-4 s$ and $4 p-3 d$ transitions originating from higher energy levels. The $\mathrm{OH}$ (first order, ultra-violet, $\left.A^{2} \Sigma^{+}, v=0 \rightarrow X^{2} \Pi, v^{\prime}=0\right)$ at $306.357 \mathrm{~nm}, \mathrm{NO}$, $\mathrm{NH}, \mathrm{O}(616 ; 777 \mathrm{~nm}, 3 \mathrm{p}-3 \mathrm{~s}), \mathrm{N}(750,825$ and $875 \mathrm{~nm}), \mathrm{N}_{2}$ $\left(C^{3} \prod_{\mathrm{u}}, v=0 \rightarrow B^{3} \prod_{\mathrm{g}}, \mathrm{v}^{\prime}=0, \varepsilon=11.1 \mathrm{eV}\right.$, second positive system), $\mathrm{N}_{2}\left(B^{3} \prod_{\mathrm{g}} \rightarrow A^{3} \Sigma_{\mathrm{u}}^{+}\right.$, first positive system), $\mathrm{N}_{2}^{+}$ $\left(B^{2} \Sigma_{\mathrm{u}}^{+}, \mathrm{v}=0 \rightarrow X^{2} \Sigma_{\mathrm{g}}^{+}, \mathrm{v}^{\prime}=0 ; 380\right.$ to $\left.475 \mathrm{~nm}\right)$ and $\mathrm{H}_{\beta}$ $(486.13 \mathrm{~nm})$ spectra and energetic UV photons were observed in the plasma plume. The reference [6] presents ac APMJ at $60 \mathrm{~Hz}$, similar to the others discussed above. They observed the later lines and $\mathrm{O}$ line at $844 \mathrm{~nm}$, this last representing a very reactive chemical species useful for bacteriological control. It is important to use a mixture of He or Ar gas with a little amount of $\mathrm{O}_{2}$, because oxygen is required to produce active species aiming polymer surface treatment, especially at high pressure. Pure $\mathrm{O}_{2}$ plasma at atmospheric pressure cause quenching of the discharge and this gas alone generate unstable plasma, with filamentary glow aspect. Therefore, the mixture with this gas with noble gases is important to produce stable APMJ, carrying selective oxygen species. Both the $\mathrm{O}$ atoms and $\mathrm{OH}$ radicals are interesting species for biomedical applications. In open-air atmospheric pressure discharges due to gas impurities and from the air wrapping up the plasma volume, most of these rotational lines are observed commonly. The analysis of the emission lines of some of these molecules and atoms, such as Ar and $\mathrm{H}$, allows estimation of the most important microplasma parameters, such as modes temperatures along the plasma jet length for a range of currents. In Fig.3, the $\mathrm{Na}$ lines were observed when the sugarcane bagasse amount were pretreated with the plasma, using a gas mixture composed with air/Ar, aiming to convert cellulose into sugar (this application will be reported in a future work). The presence of Na I doublet lines at 588.99 and $589.59 \mathrm{~nm}$ indicates collisional processes between the active species of the gas and the treated surface. These processes give an estimation of the energetic species reacting with large efficiency against the surface chemical structure of the sugarcane bagasse, because these lines represent the transition from the ground state to the upper level at $2.1 \mathrm{eV}$.

In the He APMJ driven by $4.8 \mathrm{~W}$ power consumption and flow rate of $6 \mathrm{~L} . \mathrm{min}^{-1}$, added with $2 \% \mathrm{O}_{2}$, we observed He I, $\mathrm{O}$ I and nitrogen atomic and molecular lines as $\mathrm{N}(750,825$ and $875 \mathrm{~nm}), \mathrm{N}_{2}\left(C^{3} \prod_{\mathrm{u}}, \mathrm{v}=0 \rightarrow B^{3} \prod_{\mathrm{g}}, \mathrm{v}^{\prime}=0,\right), \mathrm{N}_{2}\left(B^{3} \prod_{\mathrm{g}} \rightarrow\right.$ $\left.A^{3} \Sigma_{\mathrm{u}}^{+},\right)$and intense $\mathrm{N}_{2}{ }^{+}\left(B^{2} \Sigma_{\mathrm{u}}{ }^{+}, \mathrm{v}=0 \rightarrow X^{2} \Sigma_{\mathrm{g}}^{+}, \mathrm{v}^{+}=0\right)$ at 391 nm (see Fig.4).

Besides the He lines, the later lines appear as a result of the open air operation, where excited species of the plasma (electrons and metastables) interact chemically with the air gas neutrals, mainly $\mathrm{N}_{2}$ and $\mathrm{O}_{2}$. Ionic $\mathrm{N}_{2}{ }^{+}$at $391 \mathrm{~nm}$ and atomic oxygen lines could be result from the following reactions [10]

$$
\begin{aligned}
& \mathrm{He}^{*}+\mathrm{N}_{2} \rightarrow \mathrm{He}+\mathrm{N}_{2}^{+}+e^{-}, \text {Penning ionization } \\
& \mathrm{H} e^{+}+\mathrm{N}_{2} \rightarrow \mathrm{He}+\mathrm{N}_{2}^{+} \text {, charge transfer } \\
& e^{-}+\mathrm{N}_{2}^{+} \rightarrow \mathrm{N}_{2}^{+*}+e^{-} \text {, direct electron impact excitation } \\
& \mathrm{N}_{2}^{*}+\mathrm{O}_{2} \rightarrow \mathrm{N}_{2}+\mathrm{O}+\mathrm{O} \text {, Penning ionization }
\end{aligned}
$$

When $2 \%$ of $\mathrm{H}_{2}$ is added with the He flow, both the $\mathrm{H}_{\beta}$ line intensity and FWHM are increased. $\mathrm{H}$ atoms may be formed by reactions involving ionic $\mathrm{He}$ in $\mathrm{H}_{2}$ or in $\mathrm{He} . \mathrm{H}^{+}, \mathrm{H}_{2}^{+}$and $\mathrm{H}_{3}{ }^{+}$ions could be responsible for the observed Balmer atoms through the following reactions [11]

$$
\begin{aligned}
& \mathrm{H}^{+}+\mathrm{H}_{2} \rightarrow \mathrm{H}_{2}^{+}+\mathrm{H} \\
& \mathrm{H}_{3}^{+}+\mathrm{He} \rightarrow \mathrm{H}_{2}^{+}+\mathrm{H}+\mathrm{He} \\
& \mathrm{H}_{2}^{+}+\mathrm{He} \rightarrow \mathrm{He}^{+}+\mathrm{H}_{2}
\end{aligned}
$$

$\mathrm{H}_{2}$ may be dissociated by collision with electrons and may produce $\mathrm{H}_{\beta}$. The excitation of the $\mathrm{H}$ atoms should be done by electron impact

$$
H+e \rightarrow H^{*}+e
$$

The spectra of $\mathrm{OH}$ bands were observed due to water vapor impurities in the gas and in the atmospheric air. The populations of excited state $\mathrm{OH}\left(A^{2} \Sigma^{+}, v=0 \rightarrow X^{2} \Pi, v^{\prime}=0\right)$ at $306.4 \mathrm{~nm}$ can be generated by direct dissociation electron excitation of water or by dissociative recombination of $\mathrm{H}_{2} \mathrm{O}^{+}$, 
where this radical is formed by $\mathrm{He}$ metastables and subsequent dissociative recombination [12]

$$
\begin{aligned}
& \mathrm{H}_{2} \mathrm{O}^{+}+e^{-} \rightarrow \mathrm{OH}(\mathrm{A})+\mathrm{H}+e^{-} \\
& \mathrm{H}_{2} \mathrm{O}^{+}+e^{-} \rightarrow \mathrm{OH}(\mathrm{A})+\mathrm{H}
\end{aligned}
$$

Figure 5 show the $\mathrm{N}_{2}^{+}\left(B^{2} \Sigma_{\mathrm{u}}{ }^{+}, v=0 \rightarrow X^{2} \Sigma_{\mathrm{g}}{ }^{+}, v^{\prime}=0 ; 380\right.$ to $475 \mathrm{~nm}$ ) for Ar and He flow (added with $2 \%$ oxygen gas) at the same power consumption, $4.8 \mathrm{~W}$. One can see the $\mathrm{N}_{2}{ }^{+}$ $\left(B^{2} \Sigma_{\mathrm{u}}^{+}, v=0 \rightarrow X^{2} \Sigma_{\mathrm{g}}^{+}, v^{\prime}=0\right)$ at $391 \mathrm{~nm}$ is practically suppressed when the plasma jet is operated with $\mathrm{Ar}+2 \% \mathrm{O}_{2}$, because this APMJ spend more power to produce oxygen atoms, reducing the production of vibrational species like $\mathrm{N}_{2}{ }^{+}$[10]. The Ar I 603.2 nmline broadening (FWHM of the Lorentzian shape of the line, $\left.\Delta \lambda_{\mathrm{W}}(\mathrm{nm})=3.9 T_{g}^{0.7}\right)$ is strongly gas temperature dependent and the weakness of this line intensity is an indication of the low gas temperature of the microplasma jet.

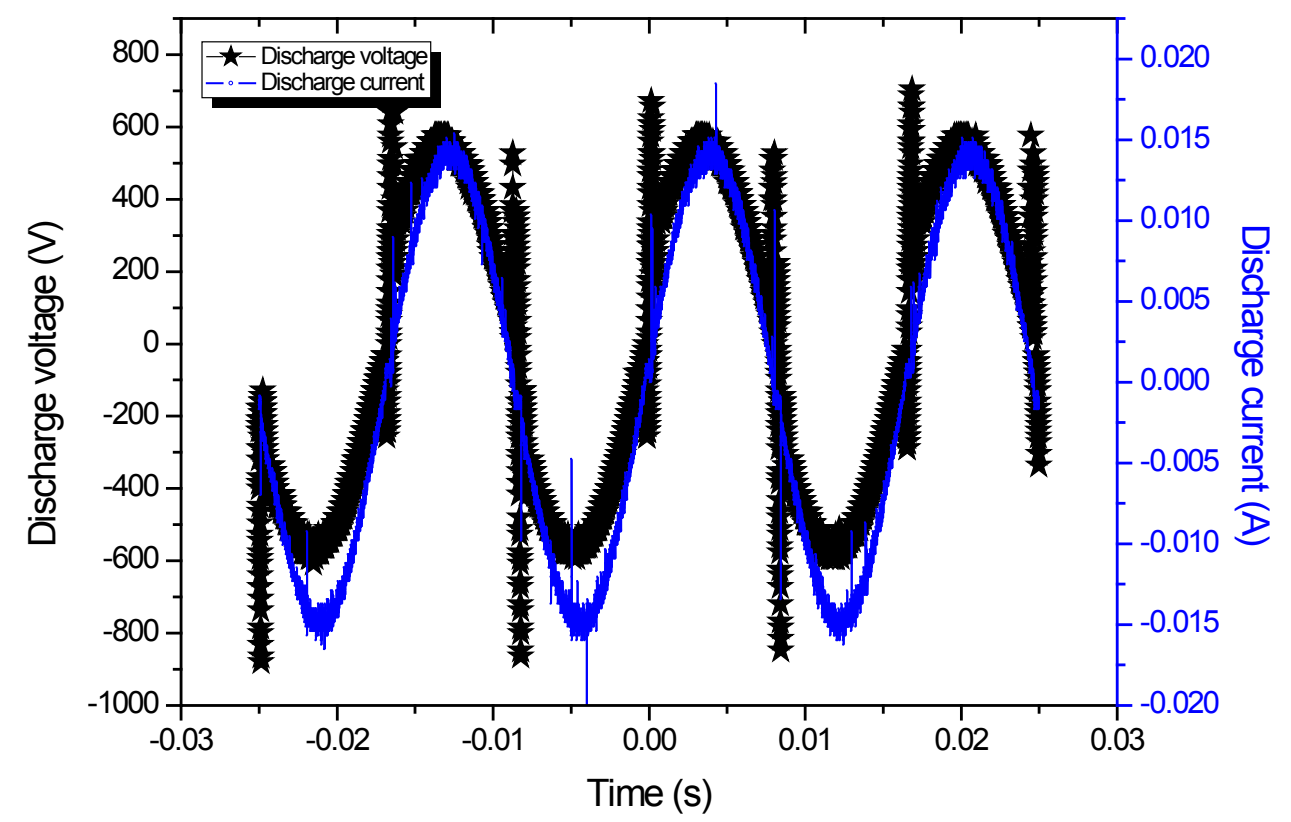

Figure 2. Voltage and current waveforms of the Ar microplasma jet at $V_{r m s}=464 \mathrm{~V}$ and $I_{r m s}=10.4 \mathrm{~mA}$ and flow rate of $61 \mathrm{~min}^{-1}$

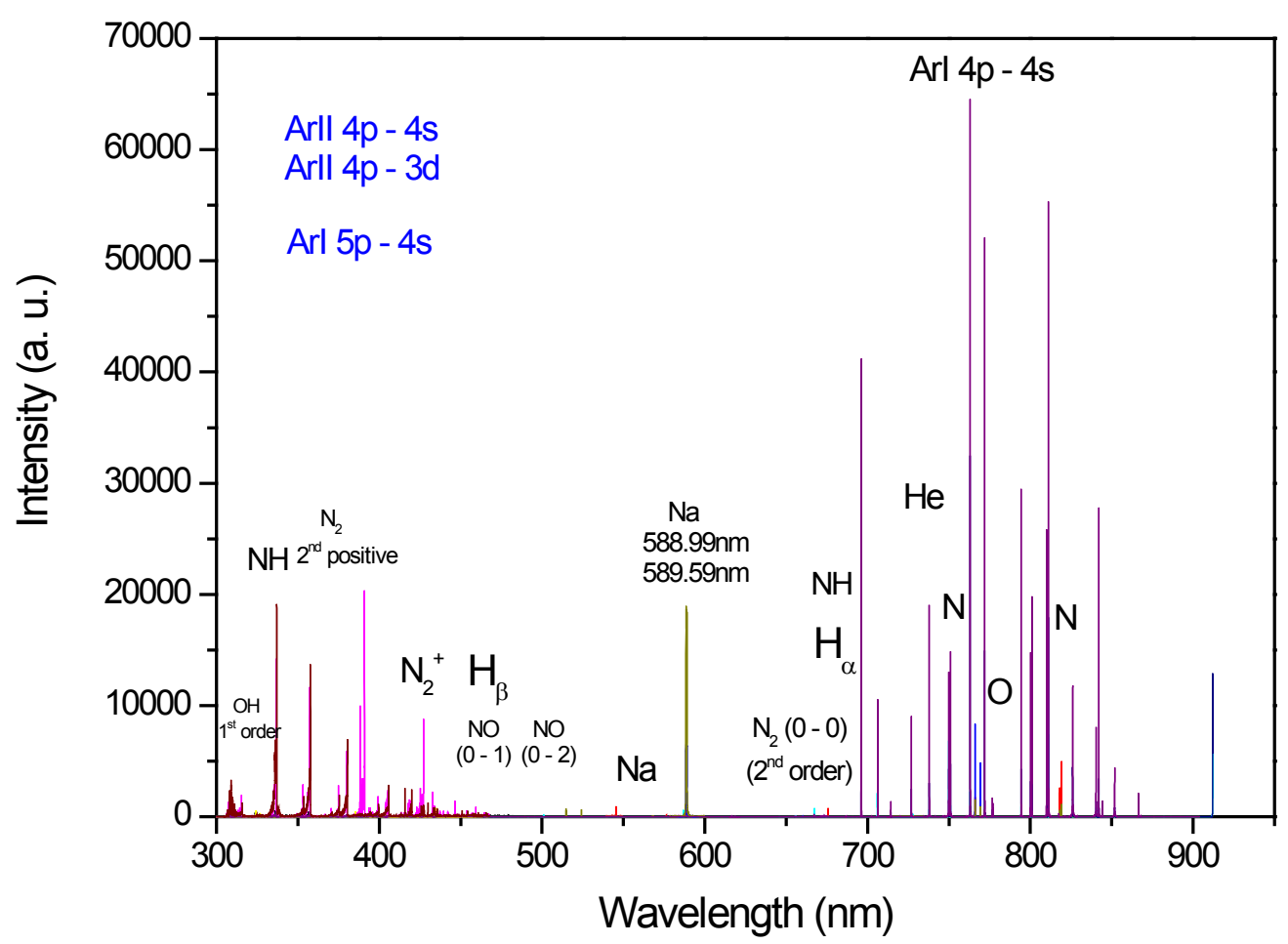

Figure 3. OES measurements for a range of gas flow at APMJ 


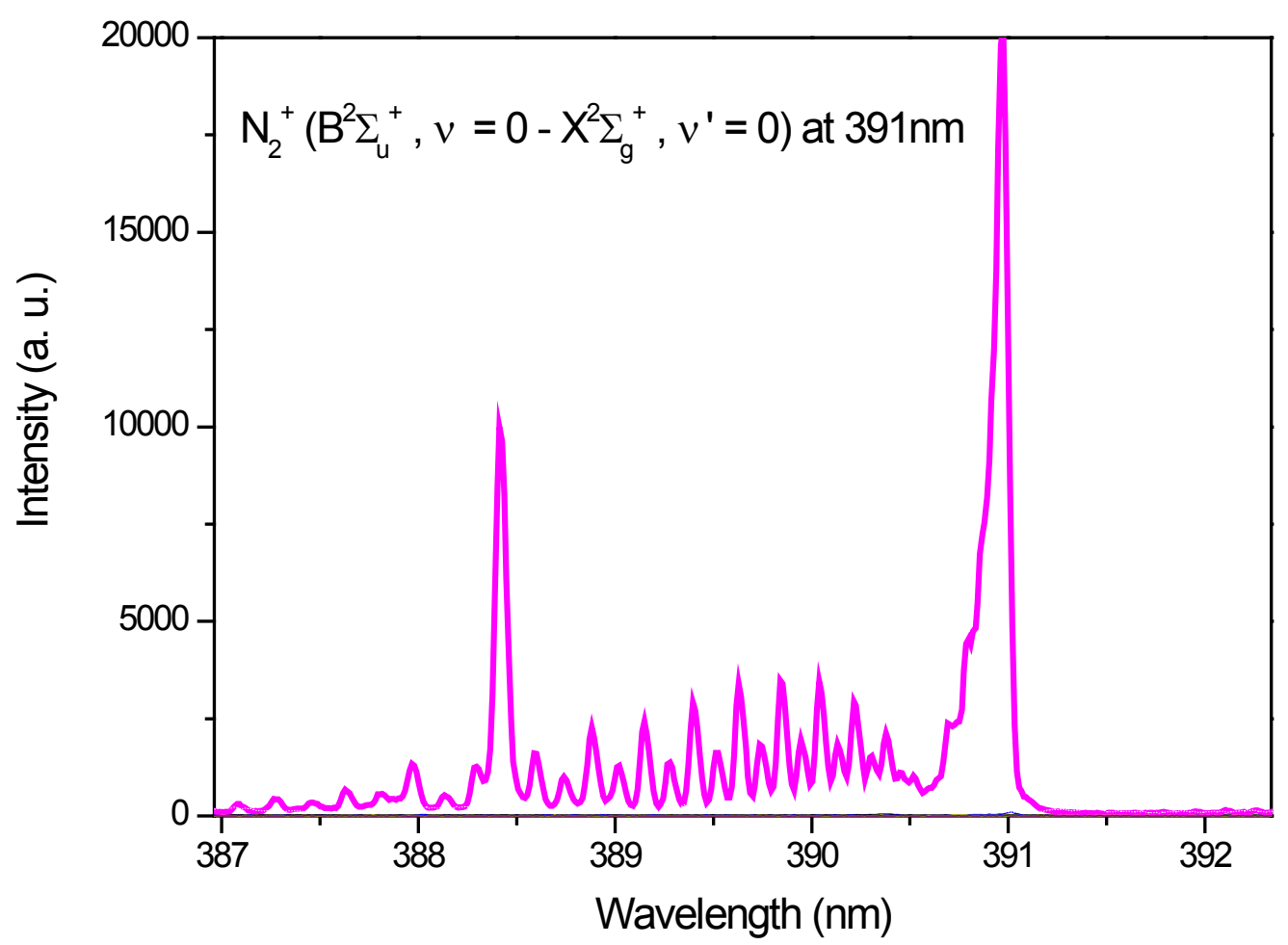

Figure 4. $\mathrm{N}_{2}{ }^{+}$at $391 \mathrm{~nm}$ for He and Ar microjet in open air

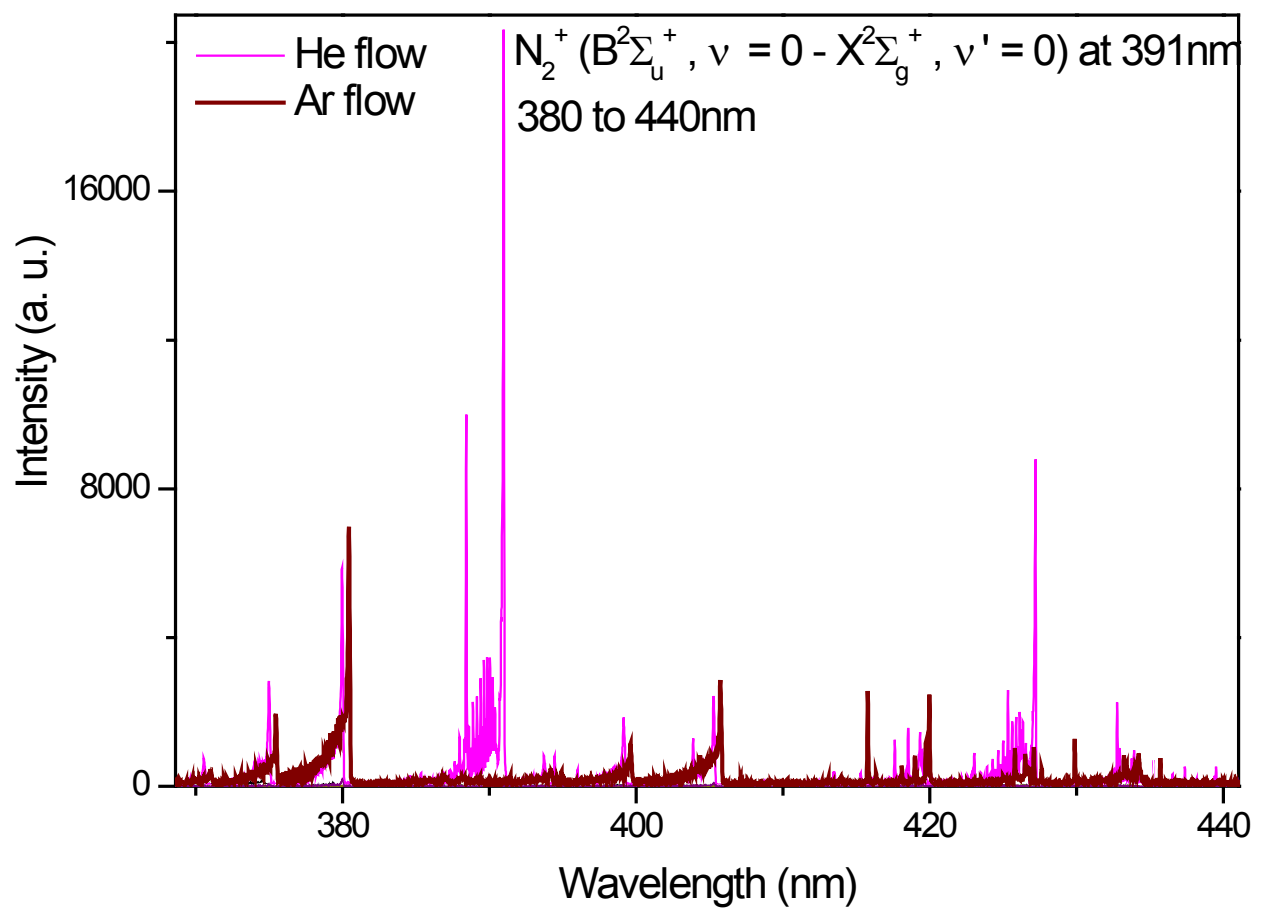

Figure 5. $\mathrm{N}_{2}{ }^{+}\left(B^{2} \Sigma_{\mathrm{u}}{ }^{+}, v=0 \rightarrow X^{2} \Sigma_{\mathrm{g}}{ }^{+}, v^{\prime}=0 ; 380\right.$ to $\left.440 \mathrm{~nm}\right)$ for Ar and He flow at the same power consumption, $4.8 \mathrm{~W}$ 
The gas temperature $T_{g}$ was estimated from analysis of the $\mathrm{OH}$ (first order, ultra-violet, $A^{2} \Sigma^{+}, v=0 \rightarrow X^{2} \Pi$, v' $=0$ ) rotational band. Figure 6 presents the experimental rotational spectrum of $\mathrm{OH}$ (first order, ultra-violet, $A^{2} \Sigma^{+}, v=0 \rightarrow X^{2} \Pi$, $\left.v^{\prime}=0\right)$ at $306.4 \mathrm{~nm}$ obtained for Ar APMJ. The $T_{r o t}$ may be taken from the Boltzmann plot (BP) [13-19]. The spectra of $\mathrm{OH}$ bands were obtained with a resolution of $0.05 \mathrm{~nm}$. These $\mathrm{OH}$ bands could be observed due to water vapor impurities in the gas, adjacent equipment and in the atmospheric air. The BP was used to obtain this molecule rotational temperature for $I_{r m s}=10.4 \mathrm{~mA}, T_{r o t}=(448 \pm 33) \mathrm{K}$ and flow of $6 \mathrm{~L} \cdot \mathrm{min}^{-1}$ for low rotational levels energy $J\left(\mathrm{Q}_{1}\right.$ branch). The APMJ gas temperature corresponds to the low $\mathrm{OH}$ rotational temperature. The gas temperature was kept constant due to the argon gas flowing between the electrodes and due to thermal conduction to the neighborhood. The plasma parameters are: gas flux $\Phi \sim 6 \mathrm{lmin}^{-1}=1.0 \times 10^{-4} \mathrm{~m}^{3} \mathrm{~s}^{-1}$; gas density $N=P k_{B}^{-1} T_{g}^{-1}=1.49 \times 10^{25} \mathrm{~m}^{-3}$; the number of argon atoms heated per second in the plasma is $n=\Phi N=1.49 \times 10^{21}$ $\mathrm{s}^{-1}$; the energy transfer to these atoms from 300 to gas temperature is $\Delta E=0.5 k_{B} n\left(8 \pi^{-1}\right)\left(T_{g}-T_{\text {room }}\right) \sim 4.6 \mathrm{~W}$, consistent with the discharge power. Figure 7 shows the second positive system $\left(C^{3} \prod_{\mathrm{u}}, v=0 \rightarrow B^{3} \prod_{\mathrm{g}}, v^{\prime}=0, \varepsilon=\right.$ $11.1 \mathrm{eV}$ ) of these molecule and Fig. 8 the rotational spectrum of the second positive system of $\mathrm{N}_{2}$ (from 334 to $336 \mathrm{~nm}-\mathrm{R}$ branch) applied to estimate the gas temperature in the plasma, where Ar metastables and excited species are present. For rotational lines belonging to the rotational levels $J^{\prime}$ varying from 14 to 28 of the $\mathrm{R}$ branch of the second positive system of nitrogenone can plot $\ln \left(I / J^{\prime 2}-1\right) \propto B_{v} J^{\prime}\left(J^{\prime}+1\right) h c / k_{B} T_{\text {rot }} \quad, \quad$ where the rotational constant $B_{v}=1.815 \mathrm{~cm}^{-1}$. The linear fit of the Boltzmann plot gives the $\mathrm{N}_{2}$ rotational temperature. Figure 9 depicts the measured $\mathrm{N}_{2}$ rotational temperature obtained from Boltzmann plot at the same conditions of Fig.6, showing higher results for $T_{\text {rot }}$ by reasons explained before.

Figure 10 show the gas temperature as a function of the discharge power, for a range of gases flowing through the microjet. The gas flow was maintained constant at $6 \mathrm{~L} \cdot \mathrm{min}^{-1}$. As stated before, this temperature was estimated from $\mathrm{OH}$ radical where we consider their rotational states and supposing that the neutral gas heavy particles are in equilibrium due to the low energies needed for excitation at this rotational level. One can see in this figure the increase rate of the temperature for all gases. For low input power the temperature is as low as the room temperature. He discharges at 5 to 6 L.min ${ }^{-1}$ gas flow show good stability and low temperature, ideal for biomedical applications. Reference [6] refers to a $\mathrm{N}_{2}$ feed ac APMJ operated at $60 \mathrm{~Hz}$. The authors found that the gas temperature varies from 300 to $500 \mathrm{~K}$ at the nozzle exit. Optical emission spectroscopy measurements allow us to infer the mean gas temperature of plasma jet from the outer electrode along its axial position. A temperature decrease up to $40^{\circ} \mathrm{C}$ was observed up to $5 \mathrm{~mm}$ and beyond this the gas temperature reaches room temperature, so enabling the APMJ to use in treatment of heat-sensitive surfaces such as biomaterials and polymers. These last measurements will be reported in a future work. Figure 3 shows a set of neutral and ionic particles, especially highly reactive ones as $\mathrm{OH}, \mathrm{O}$ and $\mathrm{N}_{2}{ }^{+}$. We can estimate the electronic temperature through Line Intensity Method, where the Saha equation is used to obtain the ratio between emitted spectral lines [13-17]. We choose the following lines (Fig.3): a) $\mathrm{Ar}^{+} 4 \mathrm{p}-4 \mathrm{~s}$ and $\mathrm{Ar} 4 \mathrm{p}-4 \mathrm{~s} ;$ b) $\mathrm{N}_{2}^{+}(391 \mathrm{~nm})$ and $\mathrm{N}_{2}$ rotational lines. Figure 11 shows the average electronic temperature which varies between 0.50 and $0.70 \mathrm{eV}$ for the full range of the gases flowing through the APMJ.

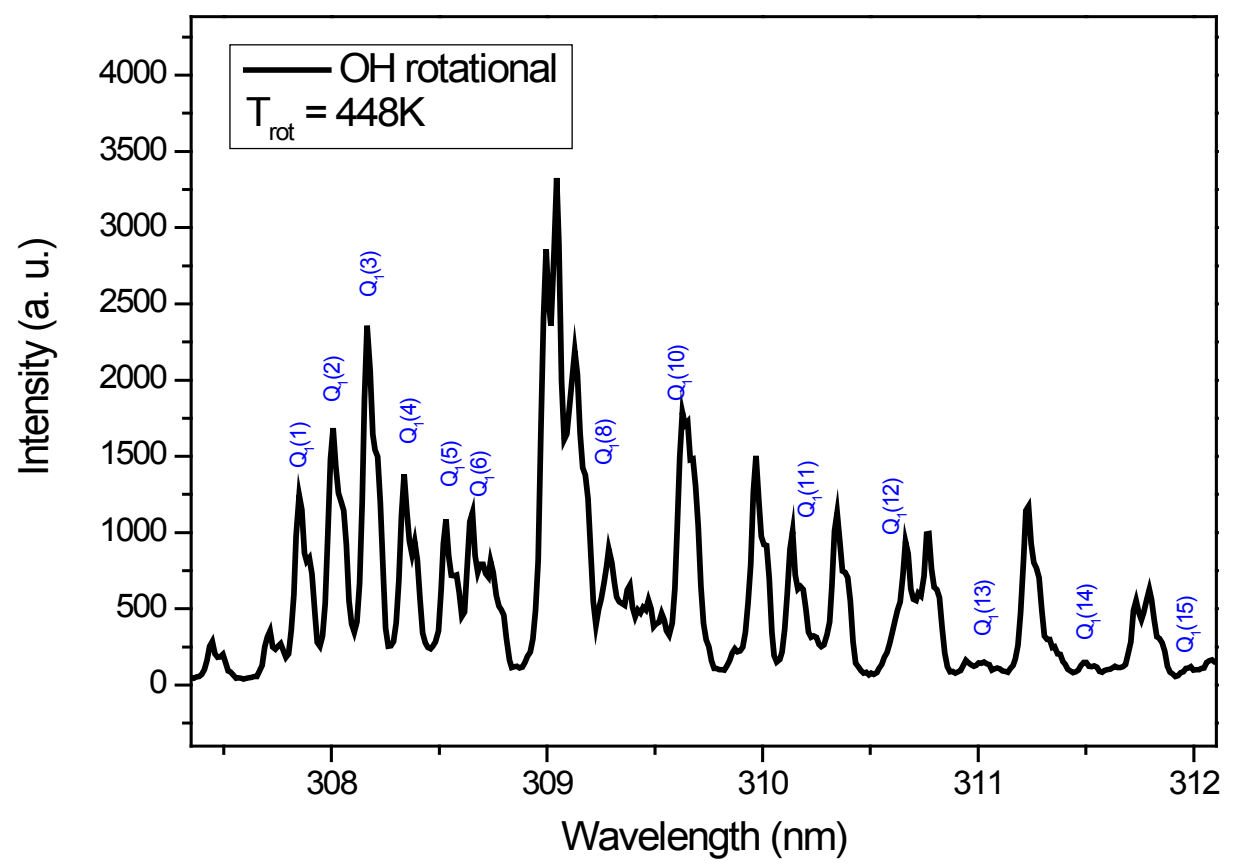

Figure 6. UV emission bands of $\mathrm{OH}$ from 308 to $312 \mathrm{~nm}\left(\mathrm{Q}_{1}\right.$ branch $)$ for Ar APMJ, $I_{r m s}=10.4 \mathrm{~mA}, T_{\text {rot }}=(448 \pm 33) \mathrm{K}$ and flow of $6 \mathrm{~L} . \mathrm{min}^{-1}$ 


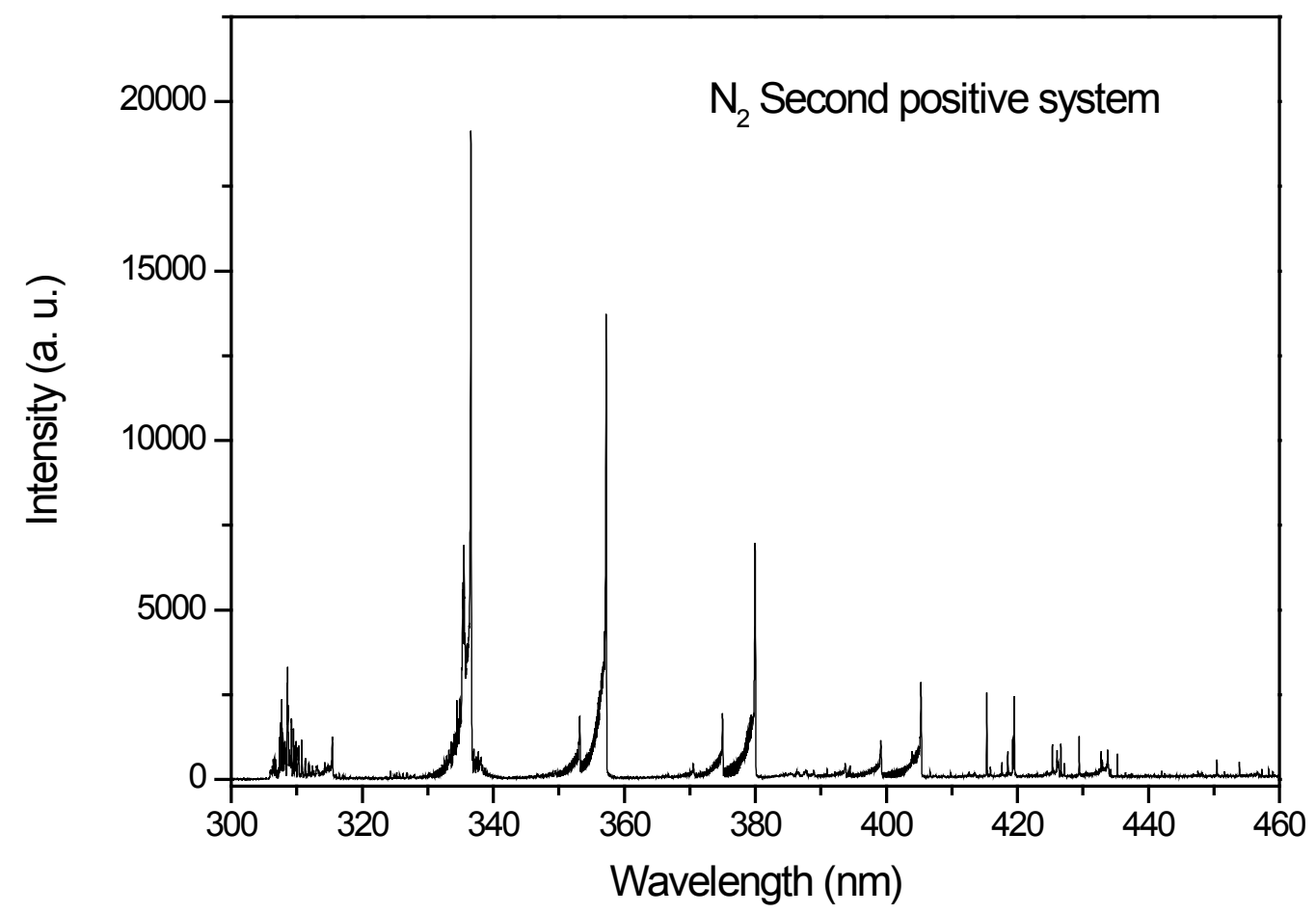

Figure 7. Second positive system of $\mathrm{N}_{2}$ from 300 to $460 \mathrm{~nm}$

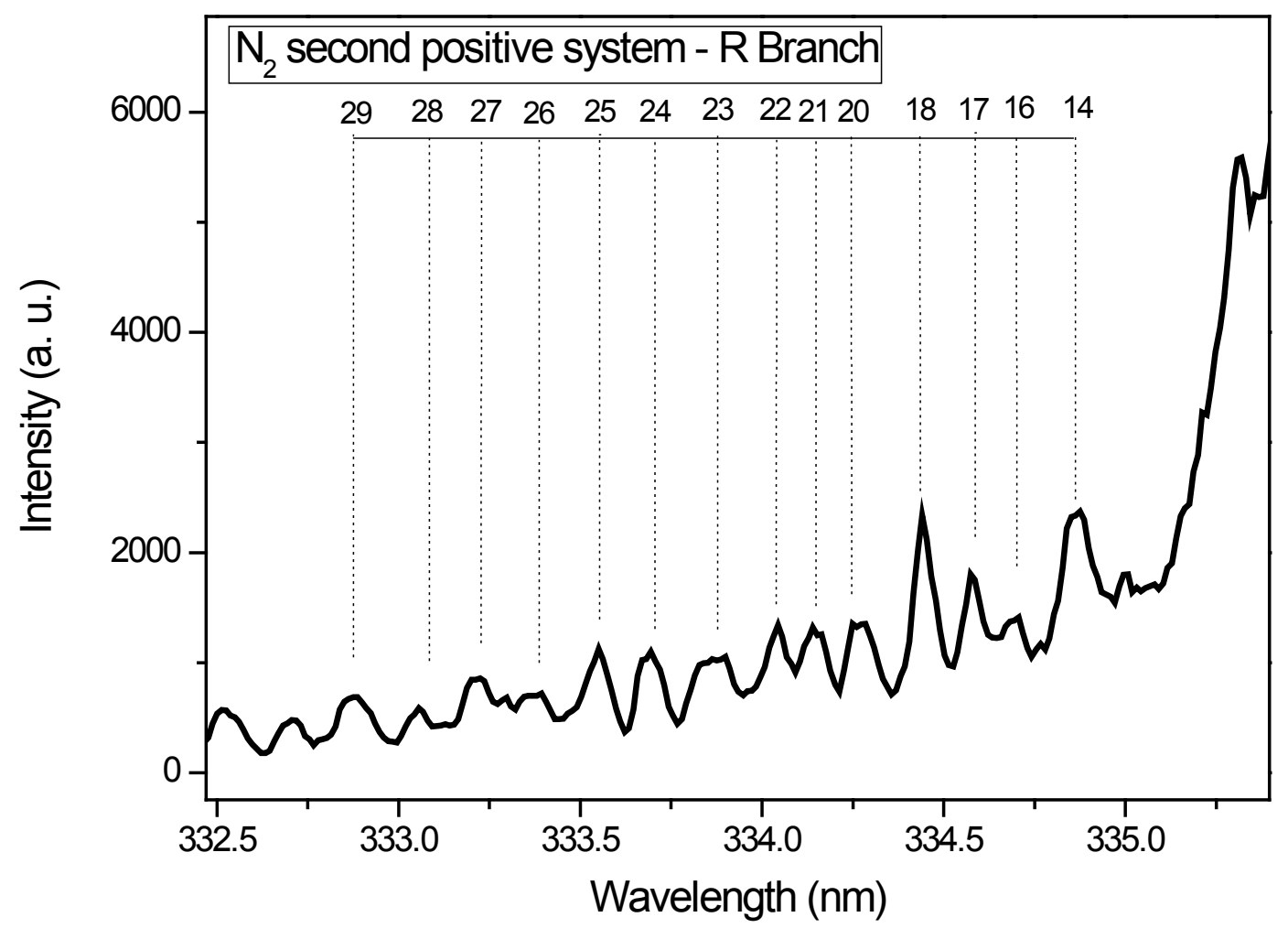

Figure 8. Rotational spectrum of the $\mathrm{N}_{2}\left(C^{3} \prod_{\mathrm{u}}, v=0 \rightarrow B^{3} \prod_{\mathrm{g}}, v^{\prime}=0\right)$ transition (R branch) 


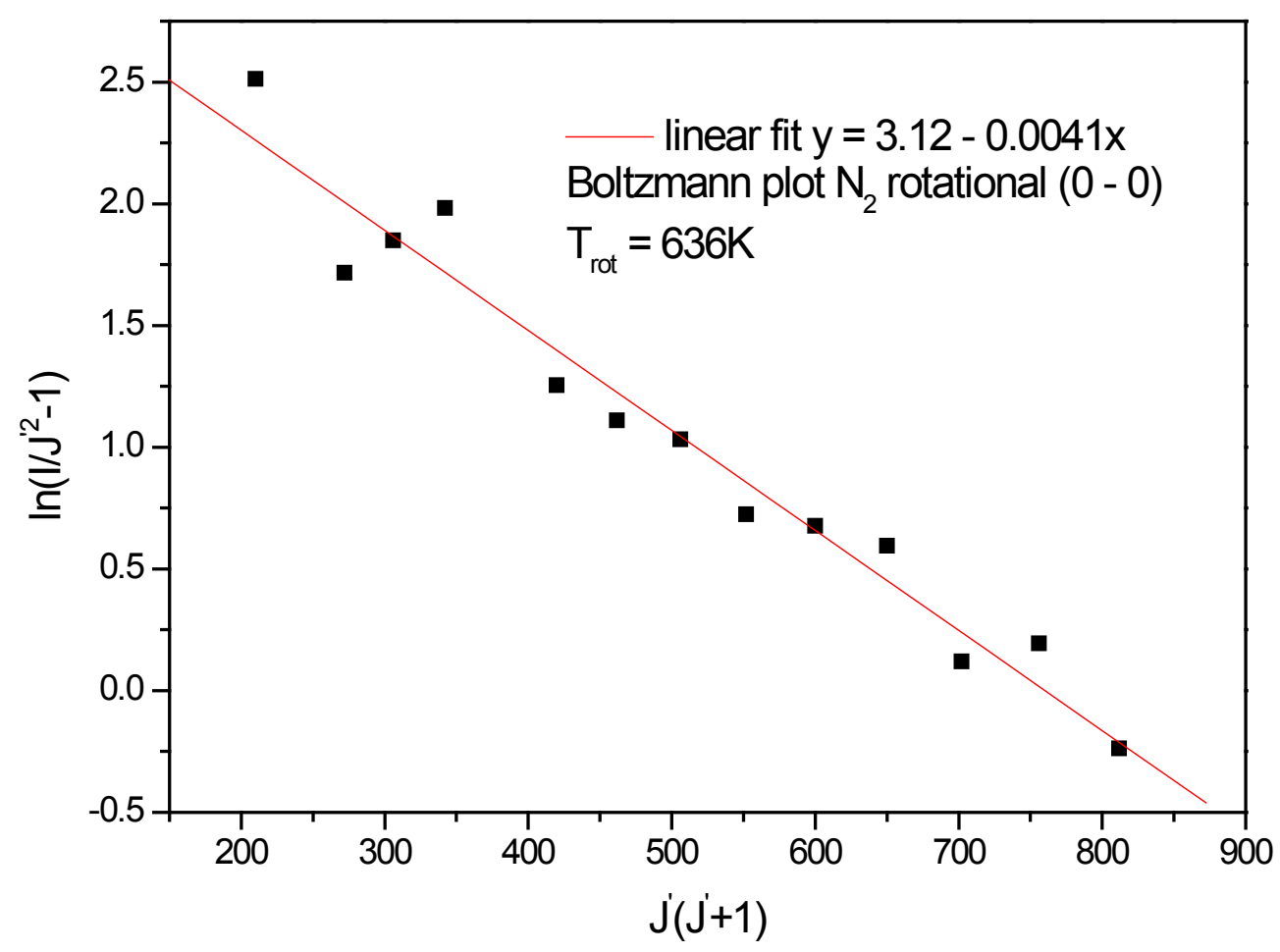

Figure 9. Boltzmann Plot of the the $\mathrm{N}_{2}(0-0)\left(C^{3} \prod_{\mathrm{u}}, v=0 \rightarrow B^{3} \prod_{\mathrm{g}}, v^{\prime}=0\right)$ (R branch) rotational transitions (see Fig.8)

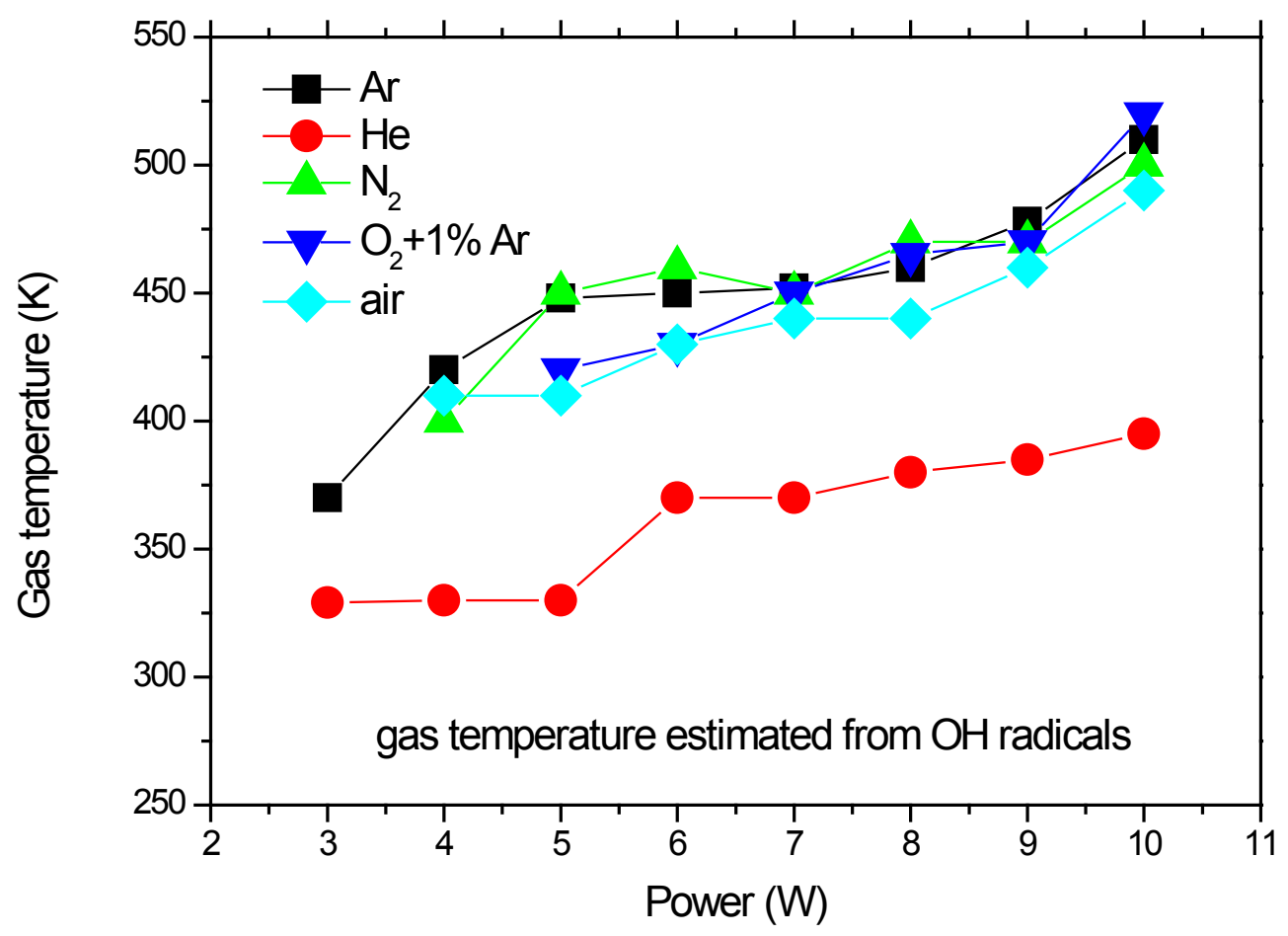

Figure 10. Gas temperature as a function of the inputpower supplied to the discharge (6L. $\mathrm{min}^{-1}$ gas flow) 


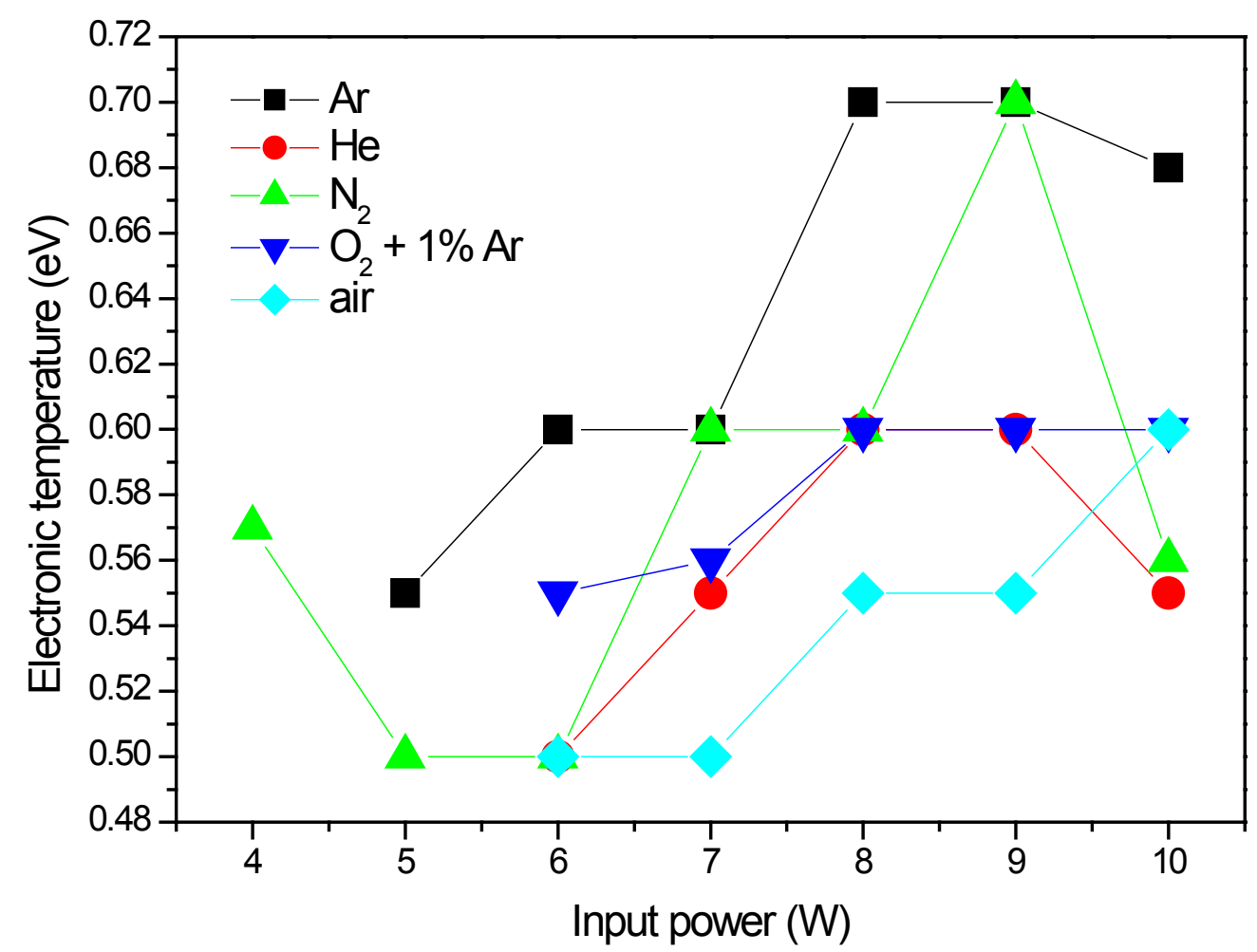

Figure 11. Electronic temperature of the discharge versus the electrical input power

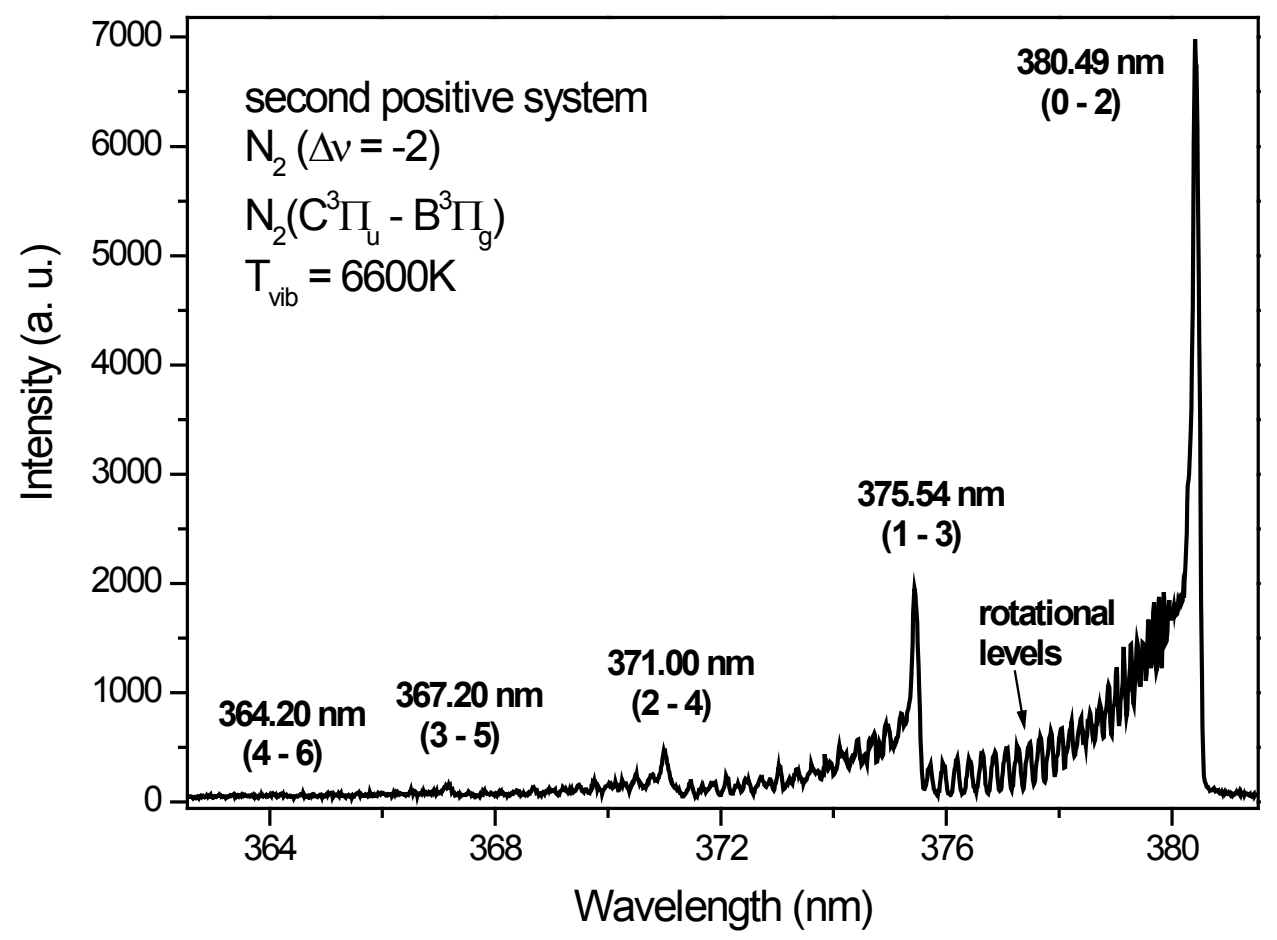

Figure 12. Vibrational distribution of the $\mathrm{N}_{2}\left(C^{3} \prod_{\mathrm{u}} \rightarrow B^{3} \prod_{\mathrm{g}}\right)$ 


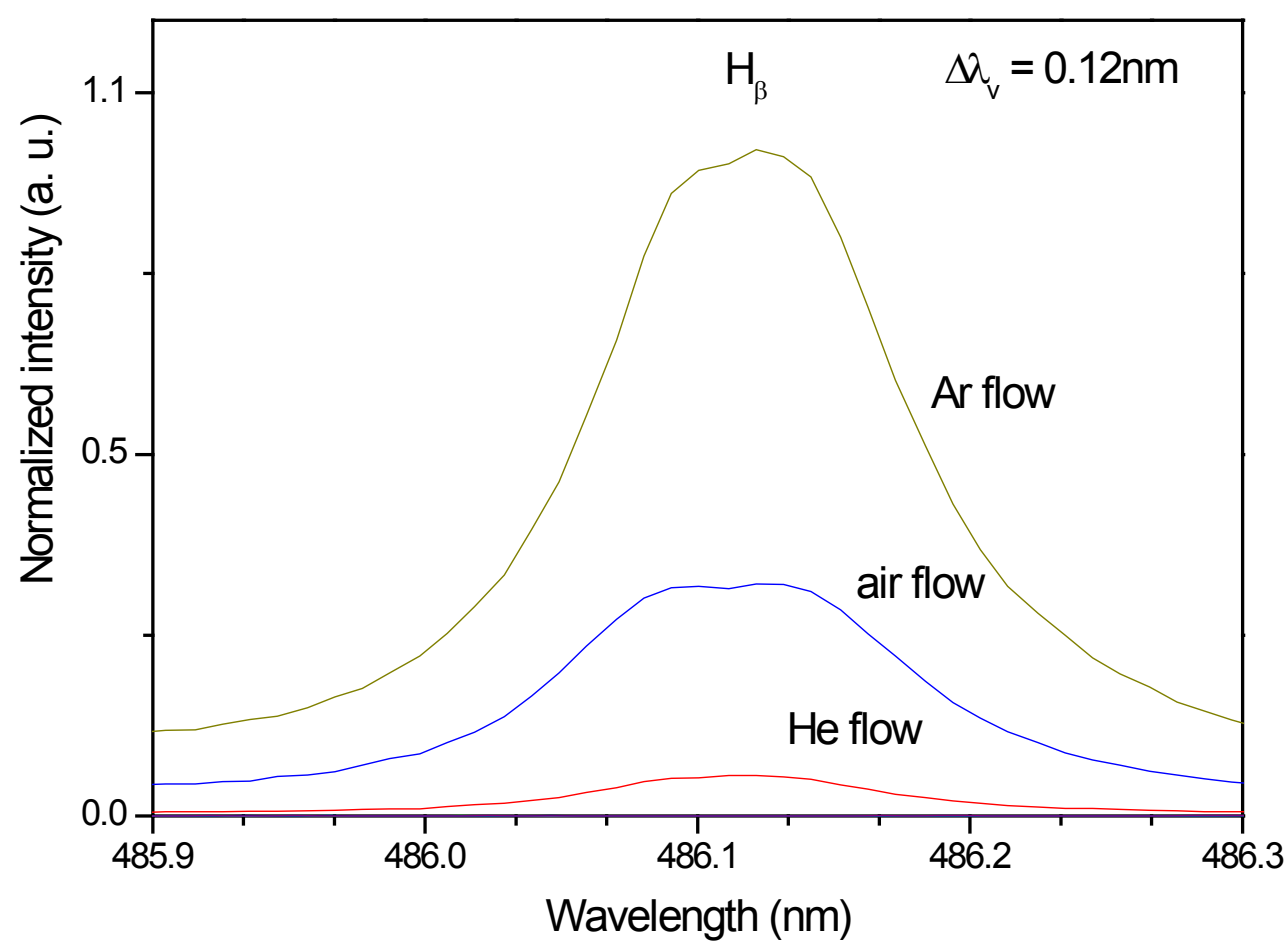

Figure 13. $\mathrm{H}_{\beta}$ line for $\mathrm{Ar}$, air and $\mathrm{He}$ flow, at the same power consumption

The Boltzmann plot method can also be applied to estimate the vibrational temperature $\left(T_{v}\right)$ in the plasma bulk using the second positive system $\mathrm{N}_{2}\left(C^{3} \prod_{\mathrm{u}} \rightarrow B^{3} \prod_{\mathrm{g}}\right)$ for $\Delta v=$ -2 . Figure 12 shows the vibrational transitions for this molecule with the corresponding band heads (input power $P$ $=8 \mathrm{~W}$ ). The temperature was in the range 0.35 to $0.57 \mathrm{~K}$ for the input power varying from 3 to $10 \mathrm{~W}$. Therefore, the difference between these three modes of temperature, $T_{e}>T_{v}>T_{g}$ indicates the partial-local thermodynamic equilibrium of the APMJ.

Figure 13 show the relative intensity of the $\mathrm{H}_{\beta}$ line, Ar, air and $\mathrm{He}$ gases flowing for the same electrical conditions, namely at $4.8 \mathrm{~W}$ power consumption. Although there are distinct relative intensity for each flow, the FWHM of the Voigt shape line is $\Delta \lambda_{v}=0.12 \mathrm{~nm}$ [13]. Unfortunately the Instrumental broadening, related to the opening slit of the monochromator, is approximately equal to $0.1 \mathrm{~nm}$ and it is impossible to obtain the gas temperature neither the electron number densities with sufficiently good accuracy using this method. Therefore, one can conclude from this figure that the gas temperature must be low $\left(T_{g}<500 \mathrm{~K}\right)$ and it is practically the same for the different gases. Compared to the dc glow discharge studied before [13], the electron number density is below than $10^{13} \mathrm{~cm}^{-3}$. According to the plasma parameters, $n_{e}=J\left(\varepsilon \mu_{e} e\right)^{-1} \sim 10^{12} \mathrm{~cm}^{-3}$.

\section{Conclusions}

The non-thermal low frequency $(60 \mathrm{~Hz})$ ac atmospheric pressure microplasma jet (APMJ) could produce stable cold glow discharges using numerous of gases such as $\mathrm{Ar}, \mathrm{He}, \mathrm{N}_{2}$,
$\mathrm{O}_{2}$ and air. The APMJ is suitable for surface treatment. The jet has a visible radial diameter of approximately $1.5 \mathrm{~mm}$ with afterglow surrounding the jet. Current and voltage measurements at flow rate of $6 \mathrm{~L} \cdot \mathrm{min}^{-1}$ show sinusoidal wave forms for flows of $\mathrm{Ar}, \mathrm{He}, \mathrm{O}_{2}+1 \% \mathrm{Ar}, \mathrm{N}_{2}$ and air gases, with rms current and voltage amplitudes of: a) $464 \mathrm{~V}, 10.4$ $\mathrm{mA}$; b) $410 \mathrm{~V}, 10.6 \mathrm{~mA}$; c) $515 \mathrm{~V}, 13 \mathrm{~mA}$; d) $430 \mathrm{~V}, 11.8 \mathrm{~mA}$ and e) $456 \mathrm{~V}, 12.9 \mathrm{~mA}$ respectively. The power absorbed by the plasma was: a) $4.8 \mathrm{~W}$; b) $4.1 \mathrm{~W}$; c) $5.8 \mathrm{~W}$; d) $4.4 \mathrm{~W}$ and e) $4.9 \mathrm{~W}$, respectively for the mentioned species. The optical measurements show the emission of important lines for bio-medical and surface treatment applications, as $\mathrm{O}, \mathrm{N}_{2}, \mathrm{O}_{3}$, $\mathrm{N}_{2}{ }^{+}, \mathrm{N}$ and $\mathrm{OH}$. Electronic temperature $\left(T_{e}\right)$ was estimated through the Line Intensity Method. The average electronic temperature varies between 0.50 and $0.70 \mathrm{eV}$ for a vast ranges of gas flow. The Boltzmann plot method was applied to estimate the vibrational temperature $\left(T_{v}\right)$ in the plasma bulk using the second positive system $\mathrm{N}_{2}\left(C^{3} \prod_{\mathrm{u}} \rightarrow B^{3} \prod_{\mathrm{g}}\right)$ for $\Delta v=-2$. The temperature was in the range 0.35 to $0.57 \mathrm{~K}$ for the input power varying from 3 to $10 \mathrm{~W}$, for all gases flow. The gas temperature $T_{g}$ was estimated analyzing the $\mathrm{OH}$ (first order, ultra-violet, $A^{2} \Sigma^{+}, v=0 \rightarrow X^{2} \Pi, v^{\prime}=0$ ) rotational band. A temperature decrease up to $40^{\circ} \mathrm{C}$ was observed up to $5 \mathrm{~mm}$ and beyond this range the gas temperature reaches the room temperature, enabling so the use of APMJ in treatment of heat-sensitive surfaces such as biomaterials and polymers. The difference between these three modes of temperature, $T_{e}>T_{v}>T_{g}$, demonstrates near PLTE condition of this plasma source. The capacity of operation with molecular and atomic (noble) gases, including air, is important for various technological applications, but the novelty of this APMJ is 
the broadening of the plasma plume at the outer electrode with diameter of $2.5 \mathrm{~mm}$ and, consequently, reaching higher surface treatment area.

\section{ACKNOWLEDGMENTS}

The authors acknowledge the financial support of the programs CAPES, FAPESP and $\mathrm{CNPq}$ for the partial financial support under Grant No. FAPESP/12/13064-4, FAPESP/PRONEX/11/50773-0, CNPq/MCTI/SECIS 406035/2013-0, CNPq/310419/2012-3 DT and CAPES/ 88881.030340/2013-01.

\section{REFERENCES}

[1] K. Kim, J. D. Choi, Y. C. Hong, G. Kim, E. J. Noh, J. S. Lee, and S. S. Yang, App. Phys. Lett.98, 073701(2011).

[2] E. J. Szili, S. A. Al-Bataineh, P. M. Bryant, R. D. Short, J. W. Bradley, and D. A. Steele, Plasma Process Polym. 8, 38 (2011).

[3] H. Ayan, E. D. Yildirim, D. D. Pappa, and W. Sun, App. Phys. Lett.99, 111502 (2011).

[4] Y. S. Seo, A-A. H. Mohammed, K. C. Woo, H. W. Lee, J. K. Lee, and K. T. Kim, IEEE Trans. on Plasma Sci.38, 2954 (2010).

[5] S. J. Kim, T. H. Chung, and S. H. Bae, Thin Film 517, 4251 (2009).

[6] Y. Hong, S. Yoo, and B. Lee, J. of Electrost.69, 92 (2011).
[7] L. Giuliani, D. Grondona, H. Kelly, and F. Minotti, J. Phys.: Conf. Series370, 012011 (2012).

[8] Y. P. Raizer, Gas Discharge Physics (Berlin: Springer, 1991)

[9] J. W. Bradley, J. S. Oh, O. T. Olabanji, C. Hale, R. Mariani, and K. Kontig, IEEE Trans. on Plasma Sci. 39,2312 (2011).

[10] H. S. Park, S. J. Kim, H. M. Joh, T. H. Chung, S. H. Bae, and S. H. Leem, Phys. of Plasma17,033502 (2010).

[11] A. V. Phelps, J. Chem. Phys.19, 653 (1990).

[12] P. Bruggeman, F. Iza, P. Guns, D. Lauwes, M. G. Kong, Y. A. Gonzalvo, C. Leys, and D. C. Schram, Plasma Sources Sci. Tech.19, 015016 (2010).

[13] B. N. Sismanoglu, J. Amorim, J. A. Souza-Corrêa, C. Oliveira, andM. P. Gomes, Spectroch. Acta Part B64, 1287 (2009).

[14] R. Caetano, Y. D. Hoyer, I. M. Barbosa, K. G. Grigorov, and B. N. Sismanoglu, Int. J. Mod. Phys. B 27, 1350089 (2013).

[15] Y. D. Hoyer, B. N. Sismanoglu, and K. G. Grigorov, The Eur. Phys. J. D 66,1712012 (2012).

[16] B. N. Sismanoglu, K. G. Grigorov, R. A. Santos, R. Caetano, M. V. O. Rezende, Y. D. Hoyer, and V. W. Ribas, The Eur. Phys. J. D60, 479 (2010).

[17] B. N. Sismanoglu, K. G. Grigorov, R. Caetano, M. V. O. Rezende, and Y. D. Hoyer, The Eur. Phys. J. D 60, 505 (2010).

[18] M. P. Gomes, B. N. Sismanoglu, and J Amorim, Braz. J. Phys.39, 25 (2009).

[19] C. Oliveira, J. A. Souza Corrêa, M. P. Gomes, B. N. Sismanoglu, and J. Amorim, Appl. Phys. Lett. 93, 041503 (2008). 